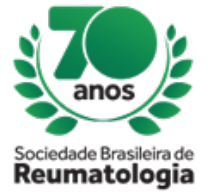

\title{
SEXUAL DYSFUNCTION IN FEMALE PACIENTS WITH SYSTEMIC LUPUS ERYTEMATHOSUS AND CORRELATIONS WITH CLINICAL PARAMETERS
}

Bruna Ferraz Gutierrez Piola (Instituto de Medicina Integral Professor Fernando Figueira - IMIP, RECIFE, PE, Brasil), Flávia Jatobá BARROS (Instituto de Medicina Integral Professor Fernando Figueira - IMIP, RECIFE, PE, Brasil), José Anchieta Brito (Faculdade Pernambucana de Saúde - FPS, RECIFE, PE, Brasil), LAURINDO FERREIRA ROCHA JR (Instituto de Medicina Integral Professor Fernando Figueira - IMIP, RECIFE, PE, Brasil)

\section{BACKGROUND}

Systemic Lupus Erythematosus (SLE) is an autoimmune disease that is most prevalent in women. The physical and mental disability caused by SLE can influence sexual function. This work aimed to evaluate whether SLE interferes in sexual function of female patients.

\section{MATERIALS AND METHODS}

We conducted a cross-sectional study with female patients classified as having SLE according to the 1987 SLE criteria of the American College of Rheumatology (ACR) or the SLICC (Systemic Lupus Erythematosus international collaborating clinics) of 2012. Clinical and sociodemographic data was collected. Disease activity was evaluated using SLE Disease Activity Index (SLEDAI). Scores of 4 and above were considered to be consistent with active disease. Sexual dysfunction (SD) was evaluated using Female Sexual Function Index (FSFI) questionnaire. The FSFI includes domains of sexual life, namely desire, arousal, lubrication, orgasm, satisfaction and pain preceding or during the sexual intercourse. The definition of SD was considered by a score less than or equal to 26.5 .

\section{RESULTS}

Fifty-one patients were included in the study, with a median age of 36 years (range 21-71), of which 38 (74.5\%) had sexual dysfunction. Years of education correlated positively with FSFI scores ( $p=0.0488$, $r=0.2773)$ and with arousal domain score $(p=0.0489, r=0.2773)$. Patients with SD correlated the mean blood pressure values with FSFI score $(p=0.0407, r=-0.3336)$, with satisfaction $(p=0.0138, r=-0.396)$, orgasm ( $p=0.0358, r=-0.3417)$, lubrication $(p=0.0293, r=-0.3538)$ and arousal $(p=0.0532, r=-0.3161)$. Patients with SD also had correlation of physician VAS score with FSFI scores ( $p=0.0407, r=-0.3638)$, with satisfaction ( $p=0.0398, r=-0.3712)$ and with arousal $(p=0.0154, r=-0.4314)$. Of note, desire score correlated with weight $(p=0.0177, r=-0.405)$ and Body Mass Index $(p=0.0044, r=-0.458)$. Taken all the women studied there was significant positive correlation of satisfaction domain with age $(p=0.0302, r=-$ 0.3038). There was a trend for the association of therapy with hydroxychloroquine and no sexual dysfuncion ( $p=0.082$ ). Thirty-six patients that had SLEDAI calculated were divided in two groups according to diease activity, in which 18 had active disease. There were no significant differences between the two groups in FSFI scores and its domains.

\section{CONCLUSION}

Disease activity seems not to be associated with sexual dysfunction in patients with SLE. FSFI scores correlated with clinical parameters of the patients with SLE. Further studies are needed with a greater number of patients and control groups. 